Copyright (C) 2015 by Academic Publishing House Researcher

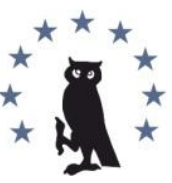

Published in the Russian Federation

European Researcher

Has been issued since 2010.

ISSN 2219-8229

E-ISSN 2224-0136

Vol. 92, Is. 3, pp. 202-207, 2015

DOI: 10.13187/er.2015.92.202

www.erjournal.ru

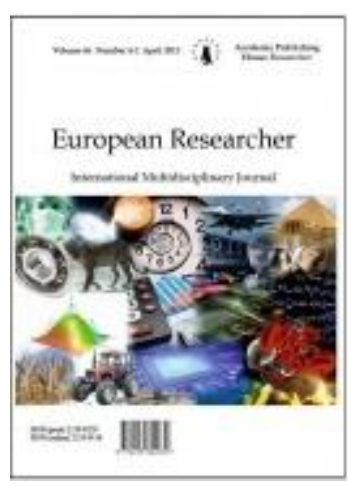

Pedagogical sciences

Педагогические науки

UDC 004:371.13

\title{
Multimedia Technologies as a Means of Boosting the Effectiveness of Student Learning in Higher Education
}

\author{
${ }^{1}$ Gulzam Abilkasimova \\ ${ }^{2}$ Lyazzat I. Uktaeva \\ 3 Laura B. Dabylova
}

\author{
${ }^{1}$ Karaganda State University. EA Buketova, Kazakhstan \\ 100024, Karaganda, etc. Miners 70, Apt. 195 \\ Ph.D., Associate Professor \\ E-mail: Botam_@mail.ru \\ ${ }^{2}$ Karaganda State University. EA Buketova, Kazakhstan \\ 101404, Temirtau, ul. Chernyshevsky 110/1, Apt. 46 \\ Senior Lecturer \\ E-mail: luktaeva@mail.ru \\ 3 Karaganda State University. EA Buketova, Kazakhstan \\ 100009, Karaganda, 6 md. 9A, Apt. 15 \\ Teacher \\ E-mail: dabilova.laura@mail.ru
}

\section{Abstract}

This article discusses multimedia technologies as a means of boosting the effectiveness of student learning in higher education, wherein they reflect present-day notions in the area of education. It goes without saying that they ought to be implemented in the practice of classes at colleges. Through the joint efforts of workers in the area of education, programmer-scientists, manufacturers of multimedia learning tools, and instructors, there is being created a new information environment wherein a key role is increasingly played by the integration of educational and information approaches to the content of education.

Keywords: multimedia; multimedia technology; multimedia courses; multimedia networks; information technology; information environment; education; student.

\section{Введение}

Одним из главных направлений образовательной политики Республики Казахстан является обеспечение конкурентоспособной нации, которая в первую очередь определяется уровнем её образованности. Главным стержнем национальной модели образования является непрерывность и преемственность её структур. Именно оно определяет уровень 
образованности нации в целом и готовит молодое поколение к жизни, реализации своего потенциала, как в личных интересах, так и в интересах общества.

Учитывая стратегическое значение Государственной программы развития образования, важным является правильный выбор современной технологии, которая должна быть внедрена в учебных заведениях и которая будет являться основой для дальнейшего развития и построения современной образовательной среды, для развития мультимедийной интерактивной среды обучения как непосредственно в классе, так и для дистанционного обучения это как элемент самостоятельной работы студентов в высшей школы и консультационной работы преподавателей [1].

В статье мы изложили результаты изучения сущности понятия «мультимедийная технология», где представлялось интересным проанализировать влияние современных мультимедийных технологий обучения на формирование познавательной самостоятельности студентов, поскольку она во многом определяет уровень знаний студентов по изучаемой дисциплине и эффективность реализации дидактического процесса.

\section{Материалы и методы}

Сегодня одной из характерных тенденций развития человеческой цивилизации является глобальная информатизация общества и активное внедрение новых информационных технологий во все сферы социальной деятельности, в том числе науку и образование.

Мультимедийные технологии это одно из наиболее бурно развивающихся направлений новых информационных технологий, используемых в учебном процессе. Мультимедийные технологии обогащают процесс обучения, позволяют сделать обучение более эффективным, вовлекая в процесс восприятие учебной информации большинство чувственных компонентов студентов [2].

Ученые отмечают, представители нынешнего поколения более развиты и физически, и умственно, чем их родители. К ним нужен особый подход в первую очередь в образовательном процессе. Поэтому в Казахстане с 2007 года с помощью передовых интеллектуальных технологий внедряется интерактивное обучение.

Необходимо отметить, что, основой образовательного процесса в высшей школы при очном обучении являются лекции, формой, адекватной уровню развития информационных технологий, следует признать мультимедийные курсы лекций, читаемые в специально оборудованных учебных аудиториях. Мультимедийные курсы могут применяться также как для индивидуального дистанционного обучения с интерактивными свойствами контроля усваиваемых знаний, так и для группового [3]. Мультимедийные технологии позволяют программно соединить слайды текстового, графического, анимационного характера с результатами моделирования изучаемых процессов

Новые подходы к мультимедийному обучению в педагогике саморазвития личности рассмотрены на основе психолого-педагогических исследований Л.И. Божович, А.Н. Бондаренко, В.В. Давыдов, Б.А. Койшибаев, Н.Н. Огольцова, М.С. Малибекова, П.И. Образцов, Е.С. Полат, А.С. Сейтбатталова, В.А. Сластенин, Е.Н. Шиянов, Д.Б. Эльконин [4-15].

\section{Результаты}

Мультимедиа это одновременное использование различных форм представления информации ее обработки в едином объекте-контейнере.

Например, в одном объекте-контейнере может содержаться текстовая, аудиальная, графическая и видео информация, а также, возможно, способ интерактивного взаимодействия с ней.

Впервые термин «мультимедиа» появился в 1965 году и активно использовался вплоть до конца семидесятых годов для описания экстравагантных для того времени театрализованных шоу, использующих разные виды и формы представления информации: слайды, кино, видео, аудио фрагменты, световые эффекты и живую музыку. В конце 1970 и начале 1980-х годов под мультимедиа понимали представления, основанные на статических или динамических изображениях от нескольких проекторов, сопровождавшихся звуком или живой музыкой. 
Термин мультимедиа также, используется для обозначения носителей информации, позволяющих хранить значительные объемы данных и обеспечивать достаточно быстрый доступ к ним (первыми носителями такого типа были CD - compact disk) [16]. В таком случае термин мультимедиа означает, что компьютер может использовать такие носители и предоставлять информацию пользователю через все возможные виды данных, такие как аудио, видео, анимация, изображение и другие в дополнение к традиционным способам предоставления информации, таким как текст.

Таким образом, средства «мультимедиа» воздействовали сразу на несколько органов человеческих чувств и представляли информацию в разных формах: визуальной, вербальной и аудиальной, что создавало (и создает) более глубокое эмоциональное воздействие, что, в свою очередь, и принесло успех и популярность этому виду театрализованных представлений. Возможность влияния на эмоциональную сферу человеческой психики является важным фактором при обучении, так как способствует более эффективному усвоению знаний. $\mathrm{B}$ течение следующего десятилетия термин «мультимедиа» включал в себя различные понятия.

В последнее время термин «мультимедиа» стал еще более многозначным. Мультимедийная вещательная компания SCALA дает следующее толкование современному понятию «мультимедиа»: «Некоторые из нас пользуются мультимедийными технологиями, включая кабельное телевидение [17]. Термин «мультимедийные сети» используется для описания мощных, стоимостью во много миллионов долларов, систем управления содержанием, используемых большими корпорациями, для обслуживания видео баз данных, а также рекламных цифровых табло и экранов. Компьютерные программы для редактирования домашнего видео, некоторые из которых сейчас уже стоят менее 100 долларов, так же могут рассматриваться как мультимедийные технологии. К техническим средствам мультимедиа также можно отнести современные мобильные телефоны, посылающие фотографии с голосовыми подписями». Мультимедиа все еще продолжает развиваться, и по мере возникновения и использования новых технологий будет включать в себя все новые понятия.

Интенсивность научно-технического прогресса постоянно нарастает и требует сбора, хранения и обработки все больших объемов информации. Величайшее достижение науки и техники XX века - компьютер дает повод для появления в создавшихся условиях научной теории перехода ноосферы в инфоноосферу, наступивший век называют веком информации и информационных технологий. Компьютер помогает повысить эффективность выполнения любой практической задачи. Компьютеризация всех областей деятельности человека требует от системы образования подготовки специалистов, владеющих новыми информационными технологиями [18].

Применение мультимедийнной технологий в образовании обладают следующими достоинствами по сравнению с традиционным обучением:

- допускает использование цветной графики, анимации, звукового сопровождения, гипертекста;

- допускает возможность постоянного обновления;

- имеет небольшие затраты на публикацию и размножение;

- допускает возможность размещения в нем интерактивных веб-элементов, например, тестов или рабочей тетради;

- допускает возможность копирования и переноса частей для цитирования;

- допускает возможность нелинейность прохождения материала благодаря множеству гиперссылок;

- устанавливает гиперсвязь с дополнительной литературой в электронных библиотеках или образовательных сайтах.

Мультимедиа позволяют сочетать вербальную и наглядно-чувственную информацию, что способствует мотивации студентов, созданию актуальной настройки на знаний.

Организация аудиторных занятий с применением мультимедийнной технологий дает возможность экономить время, тем самым интенсифицируя изложение учебного материала, за счет использования очень простых, доступных любому студенту средств. В ходе урока самими студентами может создаваться до предела визуализированная расочная учебноигровая среда, что производит буквально революционный эффект в восприятии предмета. 
Мультимедийные компьютерные технологии дают учителю возможность оперативно сочетать разнообразные средства, способствующие более глубокому и осознанному усвоению изучаемого материала, экономить время урока, насытить его информацией.

Таким образом, важная роль информационных технологий в развитии общества заключается в ускорении процессов получения, распространения и использования обществом новых знаний. Повышая качество интеллектуальных ресурсов общества, информационные технологии улучшают качество жизни.

Мультимедийные технологии (мультимедиа от анг. Multi - много, Media - среда) являются одним из наиболее перспективных и популярных педагогических информационных технологий. Они позволяют создавать целые коллекции изображений, текстов и данных, сопровождающихся звуком, видео, анимацией и другими визуальными эффектами (Simulation); включают в себя интерфейс и другие механизмы управления. Появление систем мультимедиа, безусловно, привело к революционным изменениям в области образования, в сферах профессиональной деятельности, науки, искусства [19].

Мультимедиа это множественные информационные среды - интерфейсы, обеспечивающие ввод (вывод) информации различных типов в компьютер, компьютерное создание, переработку и отображение информации различных уровней и структуры для восприятия различными органами чувств человека одновременно. Основные среды упорядоченные по возрастанию уровня, следующие: бинарные среды, контактные среды, текстовые среды, аудиопотоки, графические среды, видеопотоки, виртуальная реальность. Использование мультимедиа обеспечивает легкость восприятия информации человеком, так как человек имеет существенно отличные от компьютера средства и способы обработки информации, имеющие форму восприятия, удобную для человека.

\section{Заключение}

Таким образом, большинство вузов подключено к единой образовательной системе, о возможностях и качестве инновационного образования знают немногие. Это связано с множеством причин, в том числе и со слабой освещенностью граждан в отношении информационно-коммуникационных технологий в образовании. Большинство из них нашло свое признание, как среди студентов, так и у представителей преподавательского состава. Это обосновано тем, что применение инноваций в сфере образования, делает учебный процесс более эффективным и многофункциональным. Поскольку использование современных информационных технологий в образовании направлено не только на передачу знаний, но и на приобретение навыков работы с информационноинновационными технологиями в образовании.

\section{Примечания:}

1. Казахстан-2030. Алматы: ЮРИСТ, 2006. 152 с.

2. Христочевский С.А. Электронные мультимедийные учебники и энциклопедии // Информатика и образование. 2000. №2. С. 70-77.

3. Щеглов С.Г. Подготовка учителя к использованию на уроках электронных учебных изданий // ВКО ИПК ПРО. 2005. С. 12-15.

4. Божович Л.И. Проблемы формирования личности: Под редакцией Д.И. Фельдштейна. 2-е изд. М.: Издательство «Институт практической психологии», Воронеж: НПО «МОДЭК», 1997. 352 с.

5. Бондаренко А.Н. Компьютерные и мультимедийные образовательные технологии в профессиональной подготовке будущего учителя / М.: Миллениум, 2006. Ч 2. С. 40-47.

6. Давыдов В.В. Теория развивающего обучения / М.: Интор, 1996. 544 с.

7. Койшибаев Б.А. Педагогический мониторинг комплексного образования. Учебное пособие / Алматы: Ғылым, 2001. 155 с.

8. Огольцова Н.Н. Современные мультимедийные технологии / Новокузнецк: ИПК, 2003. C. 49-66.

9. Малибекова, M.C. Программирование на SQL: учеб. пособие / Караганда: Изд-во КарГУ, 2007. 253 c.

10. Образцов П.И. Дидактический комплекс информационного обеспечения учебной 
дисциплины в системе ДО // Открытое образование. 2001. № 5. С. 39-44.

11. Новые педагогические и информационные технологии в системе образования: учебное пособие / под ред. Е.С. Полат. М., 2000. С. 207.

12. Сейтбатталова А.С. Егоров В.В. Использование электронного учебного пособия «Организационная работа в Интернете» в дистанционном обучении студентов педагогического вуза // Актуальные проблемы современности: междун. науч. журнал. Караганда, 2008. №17. С. 221-226.

13. Сластенин В.А. Педагогика: учеб. пособие для студентов педагогических учебных заведений / М.: Школа-Пресс, 1998. 638 с.

14. Шиянов Е.Н. Гуманизация педагогического образования: состояние и перспективы. Москва; Ставрополь, 1991. 206 с.

15. Эльконин Д.Б. Развитие личности ребенка-дошкольника // Избранные психологические труды / Под ред. В. В. Давыдова. - М.: Педагогика, 1989.

16. ru.wikipedia.org/wiki

17. Авербах В.С. Создание ресурсов WWW: учеб. пособие. Самара: СГЭАКА, 2005. 124 с.: ил.

18. prodlenka.org/dopolnitelnoe

19. Советов Б.Я. Информационные технологии / М.: Юрайт, 2011. 272 с.

\section{References:}

1. Kazakhstan, 2030. Almaty: LAWYER, 2006. 152 p.

2. Hristochevsky SA electronic multimedia textbooks and encyclopedias // Informatics and education. 2000. №2. S. 70-77.

3. Goldfinches SG Preparing teachers to use the lessons of electronic textbooks // EKR IPK PRO. 2005. S. 12-15.

4. Bozovic LI. The problems of identity formation: Edited by DI Feldstein. 2nd ed. M.: Publisher "Institute of Applied Psychology," Voronezh: NPO "MODEK", 1997. 352 p.

5. AN Bondarenko Computer and multimedia educational technologies in training future teachers / M.: Millenium, 2006. Ch 2, pp. 40-47.

6. VV Davydov The theory of developmental education / M.: Intor, 1996. $544 \mathrm{~s}$.

7. Koishibayev BA Pedagogical monitoring of integrated education. Textbook / Almaty: Gylym, 2001. 155 s.

8. Ogoltsova NN Modern multimedia technology / Novokuznetsk: IPK, 2003, pp 49-66.

9. Malibekov, MS Programming in SQL: Proc. Manual / Karaganda: Publishing House of the University, 2007. $253 \mathrm{p}$.

10. Samples of PI Didactic complex information support of the discipline in the system to // Open Education. 2001. № 5. S. 39-44.

11. New pedagogical and information technologies in the education system: a tutorial / ed.

EU. Polat. M., 2000. 207 pp.

12. AS Seytbattalova Egorov VV The use of electronic textbook "Organizational work on the Internet" in distance learning pedagogy students // Actual problems of our time: Internat. scientific. magazine. Karaganda, 2008. №17. S. 221-226.

13. Slastenin VA Pedagogy: Textbook. Handbook for student teachers / M.: School-Press, 1998. $638 \mathrm{p}$.

14. Shiyanov EN Humanization of Teacher Education: Status and Prospects / Moscow; Stavropol, 1991. 206 p.

15. El'konin DB Personality development preschooler // Selected psychological works / ed.

VV Davydov. M.: Pedagogy, 1989.

16. ru.wikipedia.org/wiki

17. Auerbach VS Creating resources WWW: Proc. allowance. Samara: SGEAKA, 2005. 124 p.: ill.

18. prodlenka.org/dopolnitelnoe

19. The Council BJ Information technology / M.: Yurayt, 2011. 272 p. 
УДК 004:371.13

\title{
Мультимедийные технологии как средство повышения эффективности обучения студентов в высшей школы
}

\author{
${ }^{1}$ Гульзам Абилкасимова \\ 2 Уктаева Ляззат Идаятовна \\ 3 Дабылова Лаура Баглановна
}

${ }^{1}$ Карагандинский государственный университет им. Е.А. Букетова, Казахстан 100024, Караганда, пр. Шахтеров 70, кв. 195

Кандидат педагогических наук, доцент

E-mail: Botam_@mail.ru

${ }^{2}$ Карагандинский государственный университет им. Е.А. Букетова, Казахстан

101404, г.Темиртау, ул. Чернышевского 110/1, кв. 46

Старший преподаватель

E-mail: luktaeva@mail.ru

зКарагандинский государственный университет им. Е.А. Букетова, Казахстан

100009, Караганда, 6 мкр., 9А, кв. 15

Преподаватель

E-mail: dabilova.laura@mail.ru

Аннотация. В статье рассматривается мультимедийные технологии как средство повышения эффективности обучения студентов в высшей школы, где отображают современные представления в области образования. Естественно, они должны быть внедрены в практику занятий в вузах. Совместными усилиями работников сферы образования, ученых программистов, производителей мультимедийных средств обучения и преподавателей создается новая информационная образовательная среда в которой определяющим становится интеграция образовательных и информационных подходов к содержанию образования.

Ключевые слова: мультимедиа; мультимедийная технология; мультимедийные курсы; мультимедийные сети; информационная технология; информационная среда; образование; студент. 